\title{
Tip 2 Diabetes Mellitus Hastalarında Statin Kullanımı ve Hedefe Ulaşma Oranları: Direnç Hastada mı Hekimde mi?
}

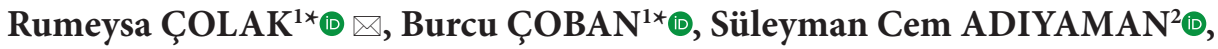 \\ Başak ÖZGEN SAYDAM²®, Barış AKINCI²® \\ ${ }^{1}$ Dokuz Eylül Üniversitesi, Tip Fakültesi, İç Hastalıkları Anabilim Dalı, İzmir \\ ${ }^{2}$ Dokuz Eylül Üniversitesi, Tıp Fakültesi, İç Hastalıkları Anabilim Dalı, Endokrinoloji Bilim Dalı, İzmir \\ * Bu araştırma makalesine Rumeysa ÇOLAK ve Burcu ÇOBAN eşit katkıda bulunmuşlardır.
}

Bu makaleye yapılacak atıf: Çolak R, Çoban B, Adıyaman SC, Özgen Saydam B, Akıncı B. Tip 2 Diabetes Mellitus Hastalarında Statin Kullanımı ve Hedefe Ulaşma Oranları:

Direnç Hastada mı Hekimde mi? Türk Diyab Obez 2019;2: 65-72.

\begin{abstract}
ÖZET
Amaç: Diyabetik bireylerde sıklıkla eşlik eden dislipidemi kardiyovasküler olaylar açısından risk artı̧ı ile karakterizedir ve hastalık sürecinde morbidite ve mortalitenin ana nedenidir. Statin tedavisi kardiyovasküler risk azalmasının temel taşıdır. Güncel kılavuzlar birçok diyabetik hastanın statin ile tedavi edilmesi gerektiğini vurgulamaktadır. Çalışmamızda Tip 2 Diabetes Mellitus (T2DM) tanılı hastalarımızda statin kullanımıyla ilgili günlük pratiğimizi ve tedavi başarı oranlarımızı güncel kılavuzlar doğrultusunda değerlendirmeyi ve hastalarımızda statin kullanmama sebeplerini inceleyerek tedavi başarısızlığının altında yatan hastaya veya hekime yönelik faktörlerin ortaya konulması amaçlanmıştır.

Gereç ve Yöntemler: Çalışmaya 2016-2018 yılları arasında Endokrinoloji ve Metabolizma Polikliniğince takipli 40 yaş ve üzeri 429

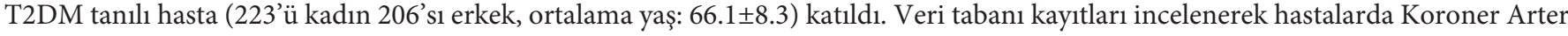
Hastalığı (KAH) varlığı, statin tedavisi kullanımı, bununla ilişkili diğer faktörler ve metabolik parametreler kaydedildi. Hastalarda statin tedavisi gereksinimi 2019 Amerikan Diyabet Cemiyeti (ADA) Kılavuzu önerileri doğrultusunda değerlendirildi.

Bulgular: Çalışmadaki hastaların ortalama LDL-K (Low Density Lipoprotein-Cholesterol-Düşük Dansiteli Lipoprotein-Kolesterol) değeri $123 \pm 43 \mathrm{mg} / \mathrm{dL}$ bulundu. Hastaların \%48.5’i statin tedavisi almaktaydı. Koroner arter hastalığı olan grupta statin kullanım oranı anlamlı olarak yüksek bulundu ( $\mathrm{p}<0.001)$. Koroner arter hastalığı olan 111 hastanın ortalama LDL-K değeri $118.3 \pm 48.0 \mathrm{mg} / \mathrm{dL}$ olup bu hastaların \%74.8'i statin kullanmaktaydı. Tedavi alan hastaların \%36.1'i etkin doz statin (atorvastatin $\geq 40 \mathrm{mg} /$ gün veya rosuvastatin $\geq 20 \mathrm{mg} /$ gün) almaktaydı. Tedavi alan hastaların \%13.2'sinde LDL-K düzeyi hedefteydi. Koroner arter hastalığı olmayan 318 hastanın ortalama LDL-K değeri $124.7 \pm 41.1 \mathrm{mg} / \mathrm{dL}$ olup bu hastaların \%39.3'ü statin kullanmaktaydı. Tedavi alan hastaların \%36'sında LDL-K düzeyi hedefteydi. Tüm çalışma grubunda statin kullanmayan hastalar değerlendirildiğinde statin tedavisi almama sebebi; \%78.9 hekimin tercihi, \%19.7 hasta tercihi, \%1.4 diğer nedenler iken; KAH olan gruptaki sebepler; \%75 hekimin tercihi; \%21.4 hasta tercihi; \%3.6 diğer nedenler olarak bulundu.

Sonuç: Bulgularımız günlük pratikte T2DM'li önemli sayıda hastada statin tedavisi verilmediği ya da tedavinin hedeflere ulaşacak şekilde intensifiye edilmediğini göstermektedir. Kardiyovasküler risk faktörlerini ve hasta-hekim tercihlerini daha derinlemesine değerlendirmek amacıyla çalışmanın birebir görüşme aşaması sürmektedir.
\end{abstract}

Anahtar Sözcükler: Kardiyovasküler risk, Koroner arter hastalğı, LDL-K, Statin, Diabetes mellitus

\section{Statin Use and Target Access Rate in Type 2 Diabetes Mellitus Patients: Resistance in Patients or Doctors?}

\begin{abstract}
Aim: Dyslipidemia associated with diabetic subjects is characterized by increased risk of cardiovascular events and is the main cause of morbidity and mortality. Statin therapy is the cornerstone of cardiovascular risk reduction. Current guidelines emphasize that many
\end{abstract}

ORCID: Rumeysa Çolak / 0000-0002-3867-0793, Burcu Çoban / 0000-0001-6956-5657, Süleyman Cem Adıyaman / 0000-0001-5404-9270, Başak Özgen Saydam / 0000-0001-9457-8919, Barış Akıncı / 0000-0002-8634-4845

Yazışma Adresi / Correspondence Address:

DOI: $10.25048 /$ tjdo.2019.42 
diabetic patients should be treated with statins. In our study, we aimed to evaluate our practice and the success rates of statin use in patients with Type 2 Diabetes Mellitus (T2DM) in accordance with current guidelines and to examine the reasons for not using statin in patients and to reveal the factors related to the patient or physician who underwent treatment failure.

Material and Methods: The study included 429 patients with T2DM (223 female, 206 male; mean age: $66.1 \pm 8.3$ years) who were followed-up by Endocrinology and Metabolism Policlinic between 2016-2018. The records of coronary artery disease (CAD), the use of statin therapy and other related factors, and metabolic parameters were recorded. The need for statin therapy in patients was evaluated according to the recommendations of the 2019 American Diabetes Association (ADA) Guidelines.

Results: The mean LDL-C (Low Density Lipoprotein-Cholesterol) of the patients was $123 \pm 43 \mathrm{mg} / \mathrm{dL}$. $48.5 \%$ of the patients were receiving statin therapy. The rate of statin use was significantly higher in CAD group $(\mathrm{p}<0.001)$. The mean LDL-C of 111 patients with known CAD was $118.3 \pm 48.0 \mathrm{mg} / \mathrm{dL}$ and $74.8 \%$ of them were using statins. $36.1 \%$ of patients receiving treatment received highdose statin. LDL-C level was targeted in $13.2 \%$ of patients receiving therapy. The mean LDL-C value of 318 patients without CAD was $124.7 \pm 41.1 \mathrm{mg} / \mathrm{dL}$. LDL-C level was targeted in $36 \%$ of patients receiving therapy. The reason for not using statin therapy in the whole study group; $78.9 \%$ physician preference, $19.7 \%$ patient preference, $1.4 \%$ other reasons; Causes in the group with CAD; $75 \%$ physician preference; $21.4 \%$ patient preference; $3.6 \%$ found as other causes.

Conclusion: Our results show that a significant number of patients with T2DM are not given statin therapy in practice, or that the treatment is not intensified to achieve the goals. In order to evaluate cardiovascular risk factors and patient-physician preferences in more depth, the one-to-one interview phase of the study is ongoing.

Key Words: Cardiovascular risk, Coronary artery disease, LDL-C, Statin, Diabetes mellitus

\section{GİRIŞ}

Tip 2 Diabetes Mellitus (T2DM), insülin salınımı ve/veya insülin duyarlılığında bozulmayla oluşan, bakım ve destek gerektiren, akut ve kronik komplikasyonlarla seyreden metabolikbir hastalıktır. Toplumlardaki diyabetik hastaların oranlarının yıllar içerisinde gösterdiği artış oldukça endişe uyandırıcıdır. Türkiye Diyabet, Hipertansiyon, Obezite ve Endokrinolojik Hastalıklar Prevalansı-II (TURDEPII) çalışması sonuçlarına göre Türkiye'deki diyabetik hasta oranı 2002 - 2010 yılları arasinda yüzde 7.8'den yüzde 13.7’ye yükselmiştir, yani yaklaşık 10 yıllık süreçte yüzde yüze yakın bir artış söz konusudur (1). 2030 yılı içinde dünyada diyabetli birey sayısının ise yaklaşık 439 milyona ulaşacağı tahmin edilmektedir. Genel olarak diyabetli hastaların diyabeti olmayanlara kıyasla yaşam beklentisinde 4-8 yil kadar azalma olduğu ve her yıl yaklaşık 1.5 milyon ölümün diyabetle doğrudan ilişkili olduğu düşünülmektedir (2). Tip 2 Diabetes Mellitus sadece karbonhidrat metabolizma bozukluğu değil aynı zamanda bir lipid ve protein metabolizması bozukluğudur. Diyabetik dislipidemi; trigliserid yüksekliği, HDL-K (High Density Lipoprotein-Cholesterol-Yüksek Dansiteli Lipoprotein Kolesterol) düşüklüğü ve LDL-K (Low Density LipoproteinCholesterol-Düşük Dansiteli Lipoprotein-Kolesterol) artışı ile karakterizedir. Hastaların yaklaşık \%70- 97'sinde bir veya daha fazla lipid bozukluğu bildirilmektedir (3). $\mathrm{Bu}$ dislipidemi ortamı beraberinde erken ve şiddetli aterosklerozla birlikte kardiyovasküler olaylar açısından anlamlı bir risk artışı yaratmaktadır. Ateroskleroz çocukluk döneminde başlayan, aterom plaklarıyla karakterize, arterlerin intima tabakalarını etkileyen bir süreçtir.
Çalışmalar aterosklerozun hiperlipidemi ve diyabetin yanısıra hipertansiyon, sigara kullanımı, immobilizasyon, hiperhomosisteinemi, hiperkoagulabilite gibi birçok faktörden etkilenen multifaktöryel bir hastalık olduğunu göstermiştir (4).

Kan kolesterol düzeyi ile koroner arter hastalığı (KAH) mortalitesi arasında lineer bir ilişki söz konusudur. Total kolesterolde her $20 \mathrm{mg} / \mathrm{dL}$ artış, KAH mortalitesinde \%12'lik bir artışa sebep olmaktadır (3). Aterosklerotik Kardiyovasküler Hastalıklar (ASKVH), T2DM’li kişilerde mortalite morbiditenin en önemli nedenidir; dolayısıyla ASKVH'nin azaltılması mortalite ve morbiditeyi azaltmak, yaşam kalitesini iyileştirmek, yaşam tarzını ve beraberinde getirdiği ekonomik yükleri azaltmak için birincil öncelik olmalıdır (5). Yapılan çalışmalar dislipidemisi olan tüm bireylerde uygun tedavi ile kardiyak ölüm, ölümcül olmayan miyokard infarktüsü, inme ve periferik arter hastalığ riskinin \%25-80 oranında azaltılabileceğini göstermektedir (6).

Statin tedavisi, T2DM'li hastalarda ASKVH azalmasının temel taşıdır ve tüm hastalarda hiperlipidemi için birinci basamak tedavi olarak kabul edilir (7). Statinler, kolesterol sentez basamaklarındaki hız kısıtlayıcı enzim olan 3-hidroksi-3-metil-glutaril-coA reduktaz inhibitörü olup, başta LDL-K değerindeki \%20-55'lik düşüş olmak üzere, trigliserid değerinde \%0-35 lik bir düşüş ve HDLK'de ise \%5-15 artış sağlayabilmektedir (8). Günlük pratiğimizde, atorvastatin $10-20 \mathrm{mg} /$ gün, rosuvastatin 5-10 $\mathrm{mg} / \mathrm{gün}$, simvastatin $20-40 \mathrm{mg} / \mathrm{gün}$, pravastatin $40-80 \mathrm{mg} /$ gün, lovastatin $40 \mathrm{mg} / g u ̈ n$, fluvastatin XL $80 \mathrm{mg} /$ gün ve 
pitavastatin 2-4 mg/gün orta doz; atorvastatin $40-80 \mathrm{mg} /$ gün, rosuvastatin 20-40 mg/gün ise yüksek doz statin olarak kullanılmaktadır $(6,9)$. Tip 2 Diabetes Mellitus'u olan 18.686 hastayı içeren bir meta-analizde, statin tedavisiyle birlikte tüm nedenlere bağlı ölümlerde \%9'luk bir azalma ve her $40 \mathrm{mg} / \mathrm{dL}(1 \mathrm{mmol} / \mathrm{L})$ LDL-K düşüşüyle majör kardiyovasküler olaylarda \%21'lik bir azalma görülmüştür (10).

Günümüzde kılavuzlar özellikle riskli hasta gruplarında statin kullanımını önermektedir. Amerikan Diyabet Cemiyeti (ADA) 2019 kılavuzu; 40 yaş altı ve 10 yıllık ASKVH riski $>\% 20$ olan hastalara yüksek doz statin tedavisi verilmesini önermekteyken, 10 yllık ASKVH riski $\leq \% 20$ olan hastalara ise rutin statin tedavisi başlanmasını önermemektedir. Ancak risk faktörlerinin [LDL-K $\geq 100 \mathrm{mg} / \mathrm{dL}$ (2.6 mmol/L), yüksek kan basincı, sigara kullanımı, kronik böbrek hasarı, albuminüri, aile öyküsü] iyi değerlendirilmesi ve kâr-zarar dengesi açısından uygun görülen hastalarda statin tedavisinin düşünülebileceğini belirtmektedir. 40 yaş ve üzeri hastalarda ise riski $>\% 20$ olan hastalara yüksek doz statin tedavisi başlanmasını, riski $\leq \% 20$ olan grupta ise orta doz statin tedavisini önermektedir. Bununla birlikte bireysel risk faktörlerinin iyi değerlendirilerek uygun görülen hastalara yüksek dozda statin tedavisinin düşünülebileceğini belirtmektedir.

Çalışmamızda T2DM tanılı hastalarımızda dislipidemi sıklığını, KAH'ın primer ve sekonder korunması amaçlı statin kullanımıyla ilgili günlük pratiğimizi ve tedavi başarı oranlarımızı güncel kılavuzlar doğrultusunda değerlendirmeyi ve hastalarımızda statin kullanmama sebeplerini inceleyerek tedavi başarısızlığının altında yatan hastaya veya hekime yönelik faktörlerin ortaya konulması amaçlanmıştır.

\section{GEREÇ ve YÖNTEMLER}

Çalışmamıza 2016 - 2018 tarihleri arasında Endokrinoloji ve Metabolizma polikliniğine başvuran hastalar arasından, Hastane Bilgi Yönetimi Sistemi (HBYS) veritabanı kullanılarak, 40 yaş ve üzeri, ADA kriterlerine göre (HbA1c $\geq \% 6.5$, açlik plazma glukozu $\geq 126 \mathrm{mg} / \mathrm{dL}$, oral glukoz tolerans testi 2 . saat plazma glukozu $\geq 200 \mathrm{mg} / \mathrm{dL}$ ve rastgele bakılan plazma glukozu $\geq 200 \mathrm{mg} / \mathrm{dL}$ olması) T2DM tanısı almış 429 hasta dahil edildi. Hastaların rutin kontrolleri sirasinda sabah 08:00-10:00 arasinda kahvaltıdan önce verdikleri venöz kan örneklerinden Roche / Hitachi D / P Moduler Sistem Otoanalizörü (Roche Diagnostics, Basel, İsviçre) yöntemiyle bakılan en güncel LDL-K değerleri, uygun kalite kontrol ve kalite güvence prosedürleri ile standart yöntemlerle ölçülen $\mathrm{HbAlc}$ değerleri incelendi. Normal referans aralığ 1 olarak LDL-K için 0-130 mg/dL,
HbA1c için \%4-5.7 alındı. Hastaların yaş, cinsiyet, eşlik eden koroner arter hastalık varlığı, diyabete yönelik aldıkları tedaviler ve statin kullanıp kullanmadıkları, dozajları, kullanmiyorlarsa sebepleri merkezimizin elektronik tıbbi kayıtlarından ve elektronik reçete bilgilerinden elde edildi. 40 yaş altı hastalar, gebeler, statin reçetesi veya $\mathrm{KAH}$ varlığı hakkında yeterli verisine ulaşılamayan hastalar çalışmaya dahil edilmedi. Hastalarda statin tedavisi gereksinimi 2019 ADA Kılavuzu önerileri doğrultusunda değerlendirildi (11). Buna göre; 40 yaş ve üzeri hastalarda 10 yıllık ASKVH riski $\% 20$ olan hastalara yüksek doz statin tedavisi başlanması, riski $\leq \% 20$ olan grupta ise orta doz statin tedavisi önerilmektedir. Bununla birlikte bireysel risk faktörlerinin (LDL-K $\geq 100 \mathrm{mg} / \mathrm{dl}$, yüksek kan basincı, sigara kullanımı, kronik böbrek hasarı, albuminüri, aile öyküsü) iyi değerlendirilerek uygun görülen hastalarda yüksek dozda statin tedavisinin başlanması düşünülebileceği belirtilmektedir.

Çalışma, Yerel Etik İnceleme Kurulu tarafından onaylandı (4534-GOA). Çalışmaya katılan tüm katılımcılarla iletişime geçilerek tıbbi kayıtlarının geriye dönük incelenmesine yönelik aydınlatılmış onam alındı.

\section{İstatistiksel Veriler}

Toplam 1736 hasta arasında Türk toplumunda Diabetes Mellitus sıklığını \%8 olarak kabul ettiğimizde çalışmamıza \%95 güven aralığı ile maksimum alınması gereken örneklem büyüklüğü 429 olarak tespit edilmiştir (12).Tüm analizler SPSS17.0 Paket programı kullanılarak yapildı. Sayısal değişkenler, ortalama ve standart sapma, kategorik değişkenler, frekans ve yüzde değerleri kullanılarak tanımlandı. Kategorik değişkenler arasındaki ilişki Spearman korelasyon analizi ile araştırıldı. İstatistiksel anlamlılık $\mathrm{p}<0.05$ olarak tanımland.

\section{BULGULAR}

Çalışmaya dahil edilen toplam 429 hastanın \%52'si kadın, $\% 48$ 'si erkek, yaş ortalaması $66.1 \pm 8.3$ ve hastaların ortalama HbAlc değeri $7.6 \pm 1.7$ ile LDL-K değeri $123 \pm 43 \mathrm{mg} / \mathrm{dL}$ idi. Hastaların \%48.5’i (208 olgu) statin kullaniyorken, \%51.5'i (221 olgu) kullanmiyordu (Tablo 1). Statin kullanan 208 hastanın \%17.7'si (37 olgu) yüksek doz, $\% 82.3$ 'ü (171 olgu) ise orta doz statin tedavisi almaktayd. Tedavi alan hastaların \%27'sinde hedef LDL-K düzeyine ulaşılmıştı. Statin kullananların \%39.9'unda ( 83 olgu); statin kullanmayanların ise \%12.7'sinde (28 olgu) eşlik eden $\mathrm{KAH}$ mevcuttu $(\mathrm{p}<0.001)$. Statin kullanan hastaların ortalama LDL-K değeri $125.8 \pm 50.4 \mathrm{mg} / \mathrm{dL}$ ve HbA1c değeri $7.7 \pm 1.7$ iken statin kullanmayan hasta grubunda ortalama LDL-K değeri $120.4 \pm 34.6 \mathrm{mg} / \mathrm{dL}$ ve HbA1c $7.4 \pm 1.8$ bulundu. Statin kullanan ve kullanmayan gruplarda cinsiyet dağılımı 
Tablo 1: Populasyonun karakteristik özellikleri.

\begin{tabular}{ll}
\hline Yaş (Ortalama \pm SS) & $66.1 \pm 8.3$ \\
\hline $\begin{array}{l}\text { Cinsiyet [n(\%)] } \\
\text { Kadın }\end{array}$ & $223(52.0)$ \\
Erkek & $206(48.0)$ \\
\hline HbA1c ( Ortalama $\pm S S)$ & $7.6 \pm 1.7$ \\
\hline LDL-K ( Ortalama \pm SS) & $123.0 \pm 43.0$ \\
\hline KAH varlı̆̆ı [n(\%)] & $111(25.9)$ \\
\hline Statin kullanımı [n(\%)] & $208(48.5)$ \\
\hline DM tedavisi [n(\%)] & $46(10.7)$ \\
Tedavisiz izlem & $206(48.0)$ \\
OAD kullanımı & $46(10.7)$ \\
İnsülin kullanımı & $131(30.5)$ \\
İnsülin+OAD kullanımı & \\
\hline LDL-K: Düşük dansiteli lipoprotein-kolesterol, HbA1c: Hemoglobin \\
Alc, KAH: Koroner arter hastalı̆ı, DM: Diyabetes mellitus, OAD: Oral \\
antidiyabetik.
\end{tabular}

açısından anlamlı farklılık gözlenmedi ( $\mathrm{p}=0.865)$. Bu iki grupta diyabet regülasyonunu ön görme amaçlı incelenen diyabete yönelik tedavilerine bakıldığında özellikle statin kullanan grupta anlamlı ölçüde insülin-oral antidiyabetik kombinasyonu kullanımı yüksek saptandı (74 olguya karşı 54 olgu, $\mathrm{p}=0.020$ ) (Tablo 2).

Eşlik eden KAH olan 111 hastanın \%44.1'i kadın \%55.9'u erkek olup yaş ortalaması $67.7 \pm 8.4$ idi. Ortalama HbA1c değeri $7.7 \pm 1.7$ ve $\mathrm{LDL}-\mathrm{K}$ değeri $118.3 \pm 48.0 \mathrm{mg} / \mathrm{dL}$ idi, \%74.8'inde (83 olgu) statin kullanımı mevcuttu, ortalama LDL-K değeri $117.3 \pm 50.4 \mathrm{mg} / \mathrm{dL}$ idi (Tablo 3 ) ve bu hastaların yalnızca \%13.2 (11 olgu) hedefteydi (LDL-K $<70$ $\mathrm{mg} / \mathrm{dL}$ ) (Şekil 1). Hastaların \%36.1'i (30 olgu) yüksek dozda (40 mg atorvastatin / 20-40 mg rosuvastatin) tedavi almaktaydı. Yüksek dozda tedavi alan hastaların ortalama LDL-K değeri ise $110.4 \pm 57.2 \mathrm{mg} / \mathrm{dL}$ idi.

Tablo 2: Statin kullanan ve kullanmayan grupların karakteristik özelliklerinin karşılaştırılması.

\begin{tabular}{|c|c|c|c|}
\hline & $\begin{array}{l}\text { Statin kullanan } \\
\quad(\mathrm{n}=\mathbf{2 0 8})\end{array}$ & $\begin{array}{c}\text { Statin kullanmayan } \\
(\mathrm{n}=\mathbf{2 2 1})\end{array}$ & $\mathbf{p}$ \\
\hline Yaş (Ortalama \pm SS) & $66.2 \pm 8.0$ & $65.9 \pm 8.5$ & 0.757 \\
\hline \multicolumn{4}{|l|}{ Cinsiyet $[\mathrm{n}(\%)]$} \\
\hline Kadın & $109(52.4)$ & $114(51,6)$ & 0.865 \\
\hline Erkek & $99(47.6)$ & $107(48,4)$ & \\
\hline HbA1c ( Ortalama \pm SS) & $7.7 \pm 1.7$ & $7.4 \pm 1.8$ & 0.110 \\
\hline LDL-K ( Ortalama $\pm S S$ ) & $125.8 \pm 50.4$ & $120.4 \pm 34.6$ & 0.199 \\
\hline KAH varlığ1 [n(\%)] & $83(39.9)$ & $28(12.7)$ & $<0.001$ \\
\hline \multicolumn{4}{|l|}{ DM tedavisi [n(\%)] } \\
\hline İnsülin kullanımı & $93(44,7)$ & $84(38.9)$ & 0.159 \\
\hline İnsülin+OAD kullanımı & $74(35.6)$ & $57(25.8)$ & 0.028 \\
\hline
\end{tabular}

LDL-K: Düşük dansiteli lipoprotein-kolesterol, HbAlc: Hemoglobin A1c, KAH: Koroner arter hastalığı, DM: Diyabetes mellitus, OAD: Oral antidiyabetik.

Tablo 3: KAH olan ve olmayan grupların karakteristik özelliklerinin karşılaştırılması.

\begin{tabular}{|c|c|c|c|}
\hline & $\begin{array}{c}\text { KAH var } \\
(\mathrm{n}=111)\end{array}$ & $\begin{array}{c}\text { KAH yok } \\
(n=318)\end{array}$ & $\mathbf{p}$ \\
\hline Yaş (Ortalama \pm SS) & $67.7 \pm 8.4$ & $65.5 \pm 8.2$ & 0.013 \\
\hline \multicolumn{4}{|l|}{ Cinsiyet [n(\%)] } \\
\hline Kadın & $49(44.1)$ & $174(54.7)$ & 0.055 \\
\hline Erkek & $62(55.9)$ & $144(45.3)$ & \\
\hline HbA1c (Ortalama \pm SS) & $7.7 \pm 1.7$ & $7.5 \pm 1.8$ & 0.526 \\
\hline LDL-K (Ortalama $\pm S S)$ & $118.3 \pm 48.0$ & $124.7 \pm 41.1$ & 0.178 \\
\hline Statin kullanımı [n(\%)] & $83(74.8)$ & $125(39.3)$ & $<0.001$ \\
\hline \multicolumn{4}{|l|}{ DM tedavisi [n(\%)] } \\
\hline İnsülin kullanımı & $60(54.1)$ & $117(36.8)$ & 0.001 \\
\hline İnsülin+OAD kullanımı & $41(36.9)$ & $90(28.3)$ & 0.089 \\
\hline
\end{tabular}

LDL-K: Düşük dansiteli lipoprotein-kolesterol, HbA1c: Hemoglobin A1c, KAH: Koroner arter hastalığı, DM: Diyabetes mellitus, OAD: Oral antidiyabetik. 
Koroner arter hastalığı eşlik etmeyen 318 hastanın \%54.7'si kadın, \%45.3'ü erkek olup yaş ortalaması $65.5 \pm 8.2$ idi. Ortalama HbA1c değeri $7.5 \pm 1.8$ ve LDL-K değeri $124.7 \pm 41.1$ $\mathrm{mg} / \mathrm{dL}$ saptandı, \%39.3'ü (125 olgu) orta veya yüksek dozda statin kullanmaktayd 1 (10-20-40 mg atorvastatin / 10-20 mg rosuvastatin), bu hastaların ortalama LDL-K değeri $131.56 \pm 49.9 \mathrm{mg} / \mathrm{dL}$ bulundu (Tablo 3), hastaların yalnızca \%36.0 (45 olgu) sında LDL-K düzeyi kılavuzların önerdiği hedefteydi (LDL-K $<100 \mathrm{mg} / \mathrm{dL}$ ).

Koroner arter hastalığ 1 olan ve olmayan grup verileri karşılaştırıldığında, cinsiyet dağılımı açısından anlamlı

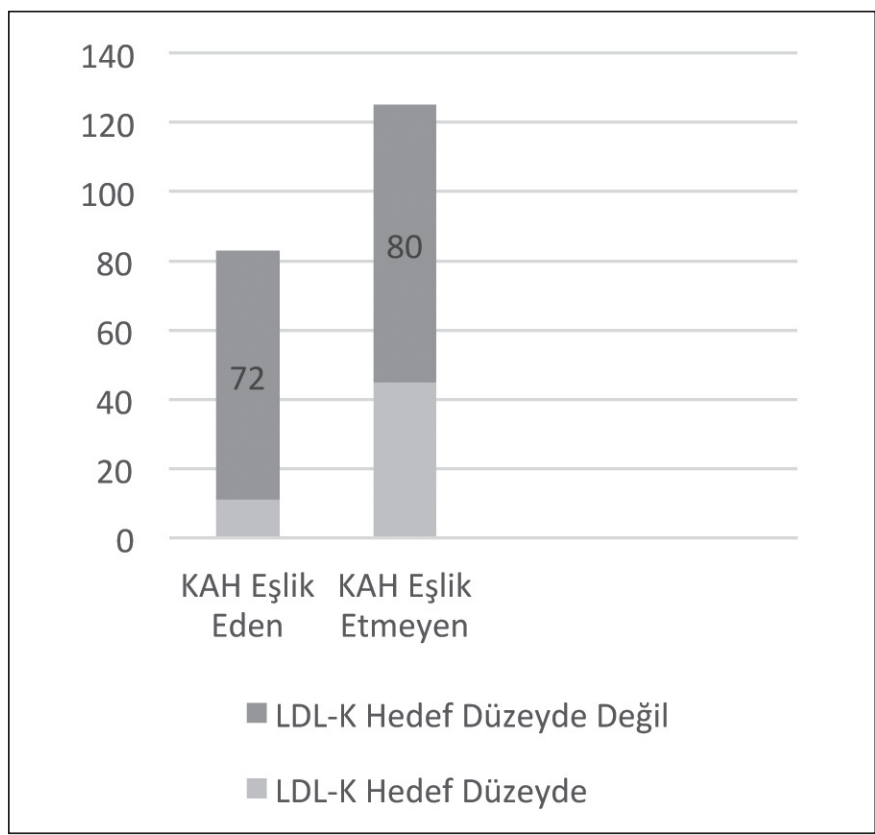

Şekil 1: LDL-K hedef başarısı.

LDL-K: Düşük dansiteli lipoprotein-kolesterol,

KAH: Koroner arter hastalığı.

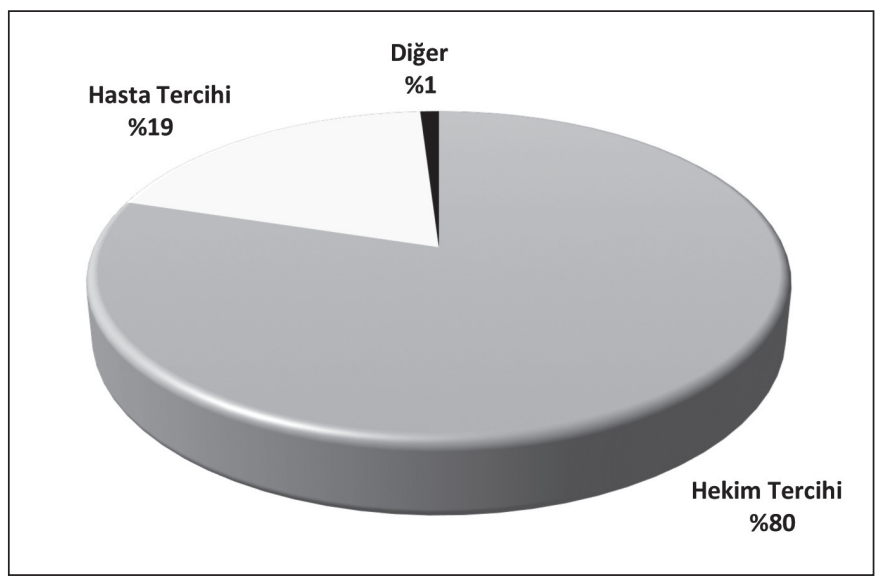

Şekil 2: Statin kullanmama sebepleri. farklılık görülmedi ( $\mathrm{p}=0.055)$ ancak yaş dağılımı açısından $\mathrm{KAH}$ olan grup lehine istatistiksel anlamlilk saptandı $(\mathrm{p}=0.013)$. Yine bakılan HbAlc ve LDL-K düzeylerinde anlamlı farklılık saptanmadı $(\mathrm{p}=0.526$ ve $\mathrm{p}=0.178)$. Statin kullanımına bakıldığında $\mathrm{KAH}$ olan grupta statin kullanım oranı anlamlı olarak yüksek bulundu $(\mathrm{p}<0.001)$. Ayrıca diyabete yönelik aldıkları tedaviler karşılaştırıldığında $\mathrm{KAH}$ pozitif grupta insülin kullanımının daha yüksek olduğu görüldü ( $\mathrm{p}=0.001$ ) (Tablo 3).

Tüm grupta statin kullanmayan hastaların statin kullanmama sebepleri incelendiğinde; \%78.9 hekimin tercihi, \%19.7 hasta tercihi, \%1.4 diğer sebepler şeklinde bulundu (Şekil 2).

Koroner arter hastalığ 1 olan grupta statin kullanımı ile ilgili yapilan alt grup analizlerinde, statin kullanan ve kullanmayan grupta cinsiyet dağılımı açısından anlamlı farklılık görülmedi ( $\mathrm{p}=0.471)$. Yine bu iki grup arasında yaş dağılımı, HbA1c ve LDL-K düzeyleri arasında istatistiksel anlamlılık bulunmadı $(\mathrm{p}=0.472, \mathrm{p}=0.292, \mathrm{p}=0.710)$, her iki grubun da diyabete yönelik aldıkları tedavilerin dağılımı benzer görüldü. Statin kullanmayan 28 kişilik grubun statin kullanmama sebepleri incelendiğinde; \%75.0 hekimin tercihi; \%21.4 hasta tercihi; \%3.6 diğer sebepler olarak saptand1 (Şekil 3).

\section{TARTIȘMA}

Tip 2 Diabetes Mellitus'lu hastalara iyi bir glisemik kontrole sahip olsalar dahi sıklıkla bir lipid anormalliği eşlik etmektedir (4). Her iki klinik durumun birlikteliğinde, kardiyovasküler riskinin daha yüksek olduğu düşünülmektedir ve artmış morbidite ve mortaliteyle ilişkilidir, bu sebeple tedavi hedeflerini iyi belirlemek oldukça önemlidir. Son yillarda yayınlanan kılavuzlarda DM bir "koroner arter hastalığı" eşdeğeri olarak tanımlanmaya başlanmıştır. Özellikle diya-

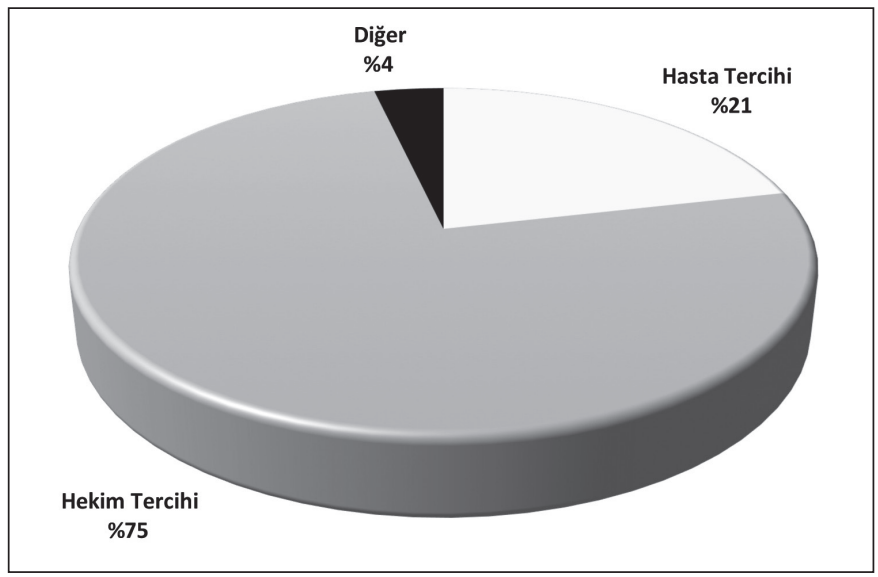

Şekil 3: KAH olan grupta statin kullanmama sebepleri.

KAH: Koroner arter hastalığ. 
betik bireylerde kardiyovasküler hastalıklar 2 ila 4 kat daha sık görülmektedir $(3,4)$. LDL-K’ün düşürülmesi, kardiyovasküler olayları 3-6 kat azaltır ve LDL-K'deki her $40 \mathrm{mg} /$ dL ( $1 \mathrm{mmol} / \mathrm{L})$ lik azalma, KVH mortalitesinde \% 20-25'lik bir azalma ile ilişkilidir (13). İngiltere'de yapılan bir meta analiz, LDL-K'deki her $40 \mathrm{mg} / \mathrm{dL}$ düşüşün $\mathrm{KVH}$ riskinde $\% 22$; stroke riskinde $\% 21$; KAH riskinde $\% 12$ ve tüm nedenlere bağlı ölüm oranlarında $\% 9$ oranında azalmayla ilişkili olduğunu göstermiştir $(10,14)$. Statinler, ASKVH'nin önlenmesinde güvenilirliği ve etkinliği kanıtlanmıs olan en önemli antihiperlipidemik ajanlardır. Tip 2 Diabetes Mellitus hastaları için LDL-K hedefi $100 \mathrm{mg} / \mathrm{dL}$ (2.6 mmol / L) nin altıdır. Birçok kılavuz T2DM'yi kardiyovasküler olay eşdeğeri olarak görmekte ve LDL-K seviyesinin $70 \mathrm{mg} / \mathrm{dL}$ (1.8 $\mathrm{mmol} / \mathrm{L}$ ) nin altına düşürülmesi gerektiğini savunmakta$\operatorname{dir}(15)$.

Tip 2 Diabetes Mellitus'lu hastalarda yapılan birkaç çalışmada, hastaların büyük bir kısmının (\%44-67) önerilen tedavi hedeflerine ulaşmadığını gösterilmiştir $(16,17) .40$ yaş ve üstü T2DM hastalarında primer korunma amaçlı lipid düşürücü ilaçlar İngiltere'de \%48'ine; İskoçya'da \%68'ine, Avustralya da ise \%64'üne reçete edildiği gösterilmiştir. Almanya'da yapılan çalışmalarda primer korunmada \%24, sekonder korunmada \%46 ve korunma durumu bilinmeyenlerde $\% 32$ oranında bir lipid düşürücü ilaç reçetelendiği gösterilmiştir (18). ABD'de ise DM'li 4075 yaş arasındaki hastaların, primer korunma için \%61'inde ve sekonder korunma için \%80'inde lipid düşürücü ilaçlar kullanılmıştır (19). Bizim çalışmamızda hastaların $\% 48.5$ 'i statin kullanmaktaydı. Koroner arter hastalığ 1 eşlik edenlerde primer korunma amaçlı statin tedavisi alanların yüzdesi \% 74.8 idi. Koroner arter hastalığı eşlik etmeyen hastalarda kilavuzlar en az orta doz statin tedavisi önermekteyken bizim hastalarımızın sadece \%39.3'ü statin kullanmaktaydı. Bu sonuçlar statin kullanımının KAH eşlik eden T2DM tanılı hastalarda KAH eşlik etmeyenlere göre daha fazla tercih edildiğini göstermektedir.

Amerikan Diyabet Cemiyeti kılavuzuna göre diyabetik bireylerde tedavi hedefleri LDL-K $<100 \mathrm{mg} / \mathrm{dL}, \mathrm{TG}<150 \mathrm{mg} /$ $\mathrm{dL}$, ve HDL-K>40 mg/dL'dir. Tedavi izleminde başağrısı, myalji, halsizlik, gastrointestinal intolerans, impotans ve doza bağlı olarak \%0.5-2 oranında karaciğer enzim yüksekliği ile \%0.2-0.4 oranında myopati görülebilmektedir (20). Çok sayıda klinik çalışmada statinlerin LDL-K düzeylerinin düşürülmesinde ve kardiyovasküler hastalıkların önlenmesinde faydalı olduğu gösterilmiştir. Diyabetin koroner arter hastalığı risk eşdeğeri olarak kabul edildiğini de göz önünde bulundurursak, klinik pratiğimizde riskli hasta grupları iyi değerlendirilmesi, endikasyonu olan hastalarda tedaviye başlanması, hatta bu süreçte çoğu zaman agresif davranılması ve hasta uyumu ile yan etki profilleri açısından hastaların takip edilmesi önem taşımaktadır. National Cholesterol Education Program Adult Treatment Panel III (NCEP-ATP III) verilerine göre gelişmiş ülkelerde bile dislipidemisi olan diyabetik bireylerin \%70- 80'inde önerilen hedeflere ulaşılamamaktadır (6). Bu

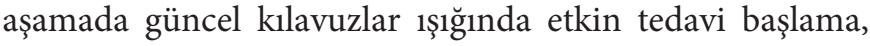
doz ayarlama ve tedavi uyumu sirasinda hekim veya hasta ilişkili çeşitli yetersizliklerin olduğunu bilmekteyiz.

Avrupa'daki EUROASPIRE çalışmasında, hastaların \%33'ünde LDL-K'ün hedefte olduğu bildirilmiştir (21). ABD'de ise yüksek LDL-K seviyesine sahip hastaların yarısından azı lipid düşürücü tedavi almış ve tedavi alanların \%33'ünden azı hedef LDL-K seviyelerine ulaşmıştır (22). Mafauzyveark. ülkegenelindediyabetikhastaların \%54'ünün LDL-K düzeyinin $<100 \mathrm{mg} / \mathrm{dL}$ olduğunu göstermiştir (23). Shariff ve ark. Malezya'daki klinik incelemelerinde LDL-K hedefe ulaşma başarısını \%13.0 bulmuşlardır (24). Gant ve ark.'nın 450 hasta üzerinde yaptığı bir çalışmada ise kardiyovasküler riski yüksek olan T2DM'li hastaların dörtte üçünde hedef LDL-K'e ulaşılmıştır. LDL-K hedefine ulaşan hastalarda statin kullanımı belirgin olarak daha sık ve statin dozu daha yüksek bulunmuştur (25). Özkan ve ark.'nın 276 diyabetik birey üzerinde yaptığ 1 bir çalışmada \%84.9'una statin başlanmış ancak hastaların sadece \%8.7'sinin etkin, \%24.3'nün ise kabul edilebilir düzeyde statin tedavisi aldığı bulunmuştur. Aynı zamanda çalışmada yetersiz hasta takibi ve tedavi uyumsuzluğuna vurgu yapılmıştır (26). Bizim çalışmamızda statin kullanan hastaların sadece \%27'sinde hedef LDL-K düzeyine ulaşılmıştı. Koroner arter hastalığı eşlik eden hastaların \%74.8' inde statin kullanımı mevcuttu, \%13.2'sinde LDL-K düzeyi hedef aralıktaydı. Koroner arter hastalığ 1 eşlik etmeyen grupta ise hastaların \%39.3'ü statin kullanmaktaydı ve \%36.0'sinda LDL-K düzeyi hedefteydi. Koroner arter hastalığ 1 eşlik eden grupta statin kullanımının daha yüksek oranda olmasına rağmen bu hastalarda hedef LDL-K'e ulaşma başarısı daha düşük olarak bulunmuştur. $\mathrm{Bu}$ da iki grup arasındaki hasta sayısındaki eşitsizlikten, hastaların başlangıç LDL-K düzeylerindeki farklılıktan ve her iki grup için de farklı LDL-K düzeyini hedef almamızdan (70 mg/dL'e karş1 100 mg/dL) kaynaklanıyor olabilir. Ayrıca $\mathrm{KAH}$ eşlik eden grup içerisinde statin verdiğimiz hastaların sadece \%36.1'i etkin doz tedavi vermiş olmamız tedavi titrasyonunda yetersiz kaldığımızı göstermektedir.

Dünya Sağlık Örgütü'ne göre, hipertansiyon, dislipidemi ve diyabet gibi hastalıklarda kronik ilaç kullanımına uymama; zaman kaybına, komplikasyonların artmasıyla da ciddi ekonomik sonuçlara yol açan önemli bir problemdir. Primer korunmada tedaviye uymama durumu değerlendirilmiş ve \%37’lik bir uyumsuzluk tespit edilmiştir. Farklı bir primer 
korunma çalışmasında hastaların yaklaşık \%51'inin statin tedavisine uymadığı bulunmuştur (27). Hwang ve ark. hekimlerin statin dozunu titre etmemelerinin ve hedef düzeylerini göz önünde bulundurmamalarının, LDL-K düzeylerinin hedefe ulaşma başarısını engelleyen faktörler arasında olduğunu belirtmiştir (28). Keskin'in 106 DM hastasını dahil ettiği çalışmasında hastaların yalnızca \%28.3'ünde LDL-K düzeyi hedefteydi, hedefte olmayan hastaların \%55.3'üne statin tedavisi verilmiş ancak hastaların ilaçlarını düzenli kullanmadığı, yan etkiler veya statinler ile ilgili yer alan olumsuz haberler sebebiyle tedaviyi yarıda bıraktığı ya da LDL-K düzey takibiyle ilaçlarının hekimleri tarafındankesildiğivurgulanmıştır (29). Bizim çalışmamızda tüm grupta hem primer hem sekonder korunmada statin kullanmayan hastaların sebepleri incelendiğinde hekimin tercihinin ön plana çıktığı görülmüştür.

Çalışmamızın bazı kısıtlılıkları vardır; KAH eşlik etmeyen ve statin kullanan hastaların ASKVH risk faktörleri içerisinden yalnızca LDL-K düzeyi incelenebilmiştir, bu nedenle 10 yıllık ASKVH risk faktörünü hesaplanamamış ve KAH eşlik etmeyen hastaların etkin dozda statin kullanıp kullanmadığı değerlendirilememiştir. Hasta anamnezlerinin retrospektif olarak incelenmesi sebebiyle statin kullanmama sebepleri ve yan etki profili yeterince irdelenememiştir. Çalışmanın bu kısıtllı̆ı̆ 1 ortadan kaldırmak ve hasta-hekim tercihi ve sebep ilişkisini daha derinlemesine değerlendirmek amacıyla çalışmanın birebir görüşme aşaması sürmektedir.

\section{SONUÇ}

Tüm sonuçlar bize statin tedavi endikasyonu koyma ve etkin dozda tedavi verme konusunda çekimser kaldığımızı ya da bilgi düzeyimizi güncel kılavuzlarla paralel ilerletemediğimizi; dislipidemiyi yeteri kadar tedavi edemediğimizi; diyabetin majör kardiyovasküler risk grubunda kabul edilen kronik bir hastalık olduğunu ihmal ettiğimizi göstermektedir. Ayrıca etkin doz tedavi alan hastaların çoğunluğunun hedefte olmaması, hekimlerin hastaları yeteri kadar bilgilendirmemesi veya uyarmamas1, hastaların yaşam tarzı değişikliklerine ve tedaviye tam uymamalarıyla ilgili bir duruma işaret ediyor olabilir. Gerek hasta eğitimi gerekse hekim farkındalıklarını artırmada ciddi ölçüde çalışmalara ihtiyaç duymaktayız.

\section{KAYNAKLAR}

1. Satman I, Omer B, Tutuncu Y, Kalaca S, Gedik S, Dinccag N, Karsidag K, Genc S, Telci A, Canbaz B, Turker F, Yilmaz T, Cakir B, Tuomilehto J; TURDEP-II Study Group. Twelveyear trends in the prevalence and risk factors of diabetes and prediabetes in Turkish adults. Eur J Epidemiol. 2013;28(2):169180.
2. Mozaffarian D, Benjamin EJ, Go AS, Arnett DK, Blaha MJ, Cushman M, et al. Heart disease and stroke statistics--2015 update: A report from the American Heart Association. Circulation. 2015;131(4):e29-322.

3. Haffner SM; American Diabetes Association. Dyslipidemia management in adults with diabetes. Diabetes Care. 2004;27 Suppl 1:S68-71.

4. Grundy SM, Benjamin IJ, Burke GL, Chait A, Eckel RH, Howard BV, et al. Diabetes and cardiovascular disease: A statement for healthcare professionals from the American Heart Association. Circulation. 1999;100(10):1134-1146.

5. Boden WE, Probstfield JL, Anderson T, Chaitman BR, Desvignes-Nickens $\mathrm{P}$, Koprowicz K, et al. Niacin in patients with low HDL cholesterol levels receiving intensive statin therapy. N Engl J Med. 2011;365(24):2255-2267.

6. Executive Summary of The Third Report of The National Cholesterol Education Program (NCEP) Expert Panel on Detection, Evaluation, And Treatment of High Blood Cholesterol In Adults (Adult Treatment Panel III). JAMA. 2001;285(19):2486-2497.

7. Warraich HJ, Wong ND, Rana JS. Role for combination therapy in diabetic dyslipidemia. Curr Cardiol Rep. 2015;17(5):32.

8. Gurm HS, Hoogwerf B. The Heart Protection Study: High-risk patients benefit from statins, regardless of LDL-C level. Cleve Clin J Med. 2003;70(11):991-997.

9. Ginsberg HN. Review: Efficacy and mechanisms of action of statins in the treatment of diabetic dyslipidemia. J Clin Endocrinol Metab. 2006;91(2):383-392.

10. Kearney PM, Blackwell L, Collins R, Keech A, Simes J, Peto R, et al. Efficacy of cholesterol-lowering therapy in 18,686 people with diabetes in 14 randomised trials of statins: A metaanalysis. Lancet. 2008;371(9607):117-125.

11. American Diabetes Association. 10. Cardiovascular disease and risk management: Standards of medical care in diabetes-2019. Diabetes Care. 2019;42(Suppl 1):S103-S123.

12. Sample size calculator.http://www.raosoft.com/samplesize. html, Erişim Tarihi:19.02.2019.

13. Mihaylova B, Emberson J, Blackwell L, Keech A, Simes J, Barnes EH, et al. The effects of lowering LDL cholesterol with statin therapy in people at low risk of vascular disease: Metaanalysis of individual data from 27 randomised trials. Lancet. 2012;380(9841):581-590.

14. Turner RC, Millns H, Neil HA, Stratton IM, Manley SE, Matthews DR, et al. Risk factors for coronary artery disease in non-insulin dependent diabetes mellitus: United Kingdom Prospective Diabetes Study (UKPDS: 23). BMJ. 1998;316(7134):823-828.

15. Brugts JJ, Yetgin T, Hoeks SE, Gotto AM, Shepherd J, Westendorp RG, et al. The benefits of statins in people without established cardiovascular disease but with cardiovascular risk factors: Meta-analysis of randomised controlled trials. BMJ. 2009;338:b2376. 
16. De Cosmo S, Viazzi F, Pacilli A, Giorda C, Ceriello A, Gentile $S$, et al. Achievement of therapeutic targets in patients with diabetes and chronic kidney disease: Insights from the Associazione Medici Diabetologi Annals initiative. Nephrol Dial Transplant. 2015;30(9):1526-1533.

17. Heintjes E, Kuiper J, Lucius B, Penning-van Beest F, Kutikova L, Liem A, et al. Characterization and cholesterol management in patients with cardiovascular events and/or type 2 diabetes in the Netherlands. Curr Med Res Opin. 2017;33(1):91-100.

18. Thomas MC, Nestel PJ. Management of dyslipidaemia in patients with type 2 diabetes in Australian primary care. Med J Aust. 2007;186(3):128-130.

19. Pokharel Y, Akeroyd JM, Ramsey DJ, Hira RS, Nambi V, Shah $\mathrm{T}$, et al. Statin use and its facility-level variation in patients with diabetes: Insight from the veterans affairs National Database. Clin Cardiol. 2016;39(4):185-191.

20. Sattar N, Preiss D, Murray HM, Welsh P, Buckley BM, de Craen AJ, et al. Statins and risk of incident diabetes: A collaborative meta-analysis of randomised statin trials. Lancet. 2010;375(9716):735-742.

21. Kotseva K, De Bacquer D, De Backer G, Ryden L, Jennings C, Gyberg V, et al. Lifestyle and risk factor management in people at high risk of cardiovascular disease. A report from the European Society of Cardiology European Action on Secondary and Primary Prevention by Intervention to Reduce Events (EUROASPIRE) IV cross-sectional survey in 14 European regions. Eur J Prev Cardiol. 2016;23(18):2007-2018.

22. Fung CSC, Wan EYF, Chan AKC, Lam CLK. Statin use reduces cardiovascular events and all-cause mortality amongst Chinese patients with type 2 diabetes mellitus: A 5-year cohort study. BMC Cardiovasc Disord. 2017;17(1):166.
23. Mafauzy M, Hussein Z, Chan SP. The status of diabetes control in Malaysia: Results of DiabCare 2008. Med J Malaysia. 2011;66(3):175-181.

24. Shariff S, Zailinawati A, Zaiton A, Ong I. A clinical audit on diabetis care in two Urban Public Primary Care Clinics in Malaysia. Malaysian Journal of Medicine and Health Sciences. 2010;6(1):101-109.

25. Gant CM, Binnenmars SH, Harmelink M, Soedamah-Muthu SS, Bakker SJL, Navis G, et al. Real-life achievement of lipidlowering treatment targets in the Diabetes and Lifestyle Cohort Twente: Systemic assessment of pharmacological and nutritional factors. Nutr Diabetes. 2018;8(1):24.

26. Özkan Y, Çolak R, Koca SS, Dağ S, Kan EK, Sırma N. Diyabet ve hiperlipidemi: Tedavide ne kadar başarılıyız? Fırat Üniversitesi Sağlık Bilimleri Dergisi. 2008;22(2):97-100.

27. Sabaté E. Adherence to long-term therapies: Evidence for action: World Health Organization; 2003 (https://www.who. int/chp/knowledge/publications/adherence_full_report. pdf?ua=1, Erişim Tarihi:19.05.2019).

28. Hwang JY, Jung CH, Lee WJ, Park CY, Kim SR, Yoon KH, Lee MK, Park SW, Park JY. Low density lipoprotein cholesterol target goal attainment rate and physician perceptions about target goal achievement in Korean patients with diabetes. Diabetes Metab J. 2011;35(6):628-636.

29. Keskin A. Diyabetes mellitus hastalarında hedef LDL kolesterol düzeylerine ulaşma durumu ve statin tedavisine uyum sıklığı. Ankara Medical Journal. 2012;12(3):122-123. 